\title{
New Biochemical Insights to Unravel the Pathogenesis of Alzheimer's Lesions
}

\author{
Alex E. Roher, Kenneth C. Palmer, John Capodilupo, Arun R. Wakade and Melvyn J. Ball
}

\begin{abstract}
Purification of amyloid plaque core proteins (APCP) from Alzheimer's disease brains to complete homogeneity and in high yield permitted its chemical fractionation and characterization of its components. APCP is mainly made of $\beta$-amyloid ( $\beta \mathrm{A}$ ) and an assortment of glycoproteins (accounting for $20 \%$ ) rich in carbohydrates compatible with $\mathrm{N}$-and $\mathrm{O}$-linked saccharides. When added to tissue culture of sympathetic and sensory neurons APCP and $\beta A$ inhibited neuritic sprouting, a reversible phenomenon at low doses. Higher concentrations of both substances kill the neurons in culture. APCP is significantly more toxic than $\beta \mathrm{A}$, suggesting the minor components may play an important role in increasing the toxicity of $\beta \mathrm{A}$. If the observed toxic effects of APCP in situ are occurring in vivo during the course of $\mathrm{AD}$, then the accumulation of these extracellular proteins could be largely responsible for some of the neuronal death observed in this neuropathology.
\end{abstract}

RÉSUMÉ: Nouveaux indices biochimiques pour élucider la pathogenèse des lésions dans la maladie d'Alzheimer. La purification, jusqu'à homogénéité complète et avec un haut redement, des protéines de base de la plaque amyloïde (PBPA) de cerveaux attaints de la maladie d'Alzheimer (MA) a permis leur fractionnement chimique et la caractérisation de leurs composants. Le PBPA est composé principalement de substance $\beta$-amylö̈de ( $\beta A$ ) et d'un assortiment de glycoprotéines (constituant $20 \%$ du PBPA), riches en hydrates de carbone, compatibles avec des saccharides unis par des ponts $\mathrm{N}$ et $\mathrm{O}$. Le PBPA et la $\beta \mathrm{A}$ inhibent le bourgeonnement neuritique, un phénomène réversible à petites doses, lorsqu'ils sont ajoutés à des neurones sympathiques et sensititifs en culture tissulaire. Des concentrations plus élevées de ces deux substances tuent les neurones en culture. Le PBPA est significativement plus toxique que la $\beta A$, suggérant que les composants mineurs peuvent jouer un rôle important en augmentant la toxicité de la $\beta A$. Si les effets toxiques observés avec le PBPA in situ surviennent in vivo pendant l'évolution de la MA, l'accumulation de ces protéines extracellulaires pourrait être responsable en grande partie de la mort cellulaire observée dans cette neuropathologie.

Can. J. Neurol. Sci. 1991; 18: 408-410

The major histopathological lesions observed in Alzheimer's disease (AD) brains are neuronal cell loss, the accumulation of intracellular neurofibrillary tangles made of paired helical filaments (PHF) and neuritic plaques (NP). Along with these lesions there appears to be an active participation of the immune system.1-2 Immunoglobulins, complement proteins, reactive microglia, as well as T-helper and T-cytotoxic suppressor lymphocytes have been demonstrated in AD brain tissue. Most of the neurons in AD apparently disappear in an abrupt way, showing no morphological evidence of their morbid decline. This phenomenon would account for most of the severe neuronal dropout and atrophy of the brain observed in AD. However, a relatively small number of neurons apparently experiences a chronic pathological transformation. The synthesis and accumulation of PHF filling the neuronal perikaryon and extensively distributed along the neurites support this idea. The fact that PHF are encountered in numerous neurodegenerative disorders, and to a lesser extent in the aged brain, implies PHF accumulation is a usual cellular response to a number of diverse pathogenetic causes.
We suggest that the accumulation of undegradable PHF is a common mechanism of defense on the part of some neurons in which the architectural integrity of their neuritic arbor, and its underlying axonal flow and organelle distribution are compromised. In support of this proposal is the electron microscopic (EM) observation of the inverse relationship which exists between the neuritic mass of microtubules and the PHF. In addition, EM examination of PHF in biopsies obtained from AD patients has suggested an association between these structures and cytomembranes. ${ }^{3}$ PHF are often observed as apparently arising at or from the surface of intracellular membranes which form irregular stacks of lamellated bodies. It is possible that the protein core of PHF, which has remained resistant to biochemical characterization, may be derived from a common intrinsic protein involved in organelle translocation. As illustrated by the $\beta$-amyloid $(\beta A)$, for thermodynamic reasons intramolecular hydrophobic domains, when exposed to a polar environment, can induce conformational changes that generate \%ry stable and insoluble polypeptides.

From the Departments of Anatomy and Cell Biology (A.E.R., J.C.), Pathology (K.C.P.) and Pharmacology (A.R.W.), Wayne State University School of Medicine, Detroit and Division of Neuropathology (M.J.B.), Oregon Health Sciences University, Portland

Reprint requests to Dr. Alex E. Roher, Department of Anatomy and Cell Biology, Wayne State University School of Medicine, 540 E. Canfield Ave., Detroit, Michigan, U.S.A. 48201 
Neuritic plaques are spherical structures composed of an extracellular deposition of amyloid filaments and a heterogeneous assortment of glycoproteins, designated as the amyloid plaque core proteins (APCP). ${ }^{4}$ These proteins may be condensed at the center of the plaque enveloped and infiltrated by dystrophic neurites and by cytoplasmic projections from microglia and astrocytes. In addition to their location within NP, the APCP also can be diffusely and abundantly distributed in the neuropil. The extracellular amyloid is mainly composed of a collection of very flexible unbranched fibrils, $10 \mathrm{~nm}$ in diameter, of variable length. The $\beta \mathrm{A}$ fibril results from the polymerization of a 42 amino acid polypeptide derived from the anomalous proteolytic cleavage of a larger precursor, the $\beta$-amyloid precursor protein $(\beta A P P)$, having the characteristics of a membrane receptor. ${ }^{5}$ Currently, four transcriptional forms of the membrane bound $\beta A P P$, known as $\beta A P 695, \beta A P 714, \beta A P 751$ and $\beta A P 770$, have been identified. ${ }^{5-10}$ The last two forms include an insert which resembles a Kunitz-type protease inhibitor.

Lately, it has been established that the N-terminal sequence of the $\beta A P P$ is identical to that of the protease inhibitor nexin II, ${ }^{11,12}$ which also has the capacity of complexing with the gamma subunit of nerve growth factor. A more recent homology has been found between the $\beta A P P$ and the platelet coagulation factor XIa-inhibitor. ${ }^{13}$ Immunochemical studies utilizing antisera raised against synthetic peptides representing $\mathrm{N}$-and $\mathrm{C}$-terminal sequences of the $\beta A P P$, have identified a group of membrane associated proteins, with a molecular weight in the range of 10-130 kd, in brain and non-neural tissues. ${ }^{14}$ It has also been established that this group of proteins contain $\mathrm{N}$-and O-linked glycosylated groups as well as tyrosine sulfate. ${ }^{15}$ The synthesized $\beta$ APP molecules apparently have a rapid turnover, since they exhibit a short half life of approximately $30 \mathrm{~min} .15$ Moreover, it has been reported that the BAPP messenger RNA (mRNA) represents around $0.1-0.2 \%$ of the total mRNA found in the brain tissue. ${ }^{16}$ These findings are of great consequence because they suggest that only a very small amount of the BAPP, if produced in the neural tissue, at any given time, is abnormally processed to yield $\beta A$ filaments. Accumulation of insoluble and undegradable $\beta \mathrm{A}$, therefore, may be a slow and chronic phenomenon which may have been initiated well before the onset of the patient's clinical symptoms of dementia.

In relation to the neuritic plaque, a battery of antibodies, raised against regions of the $\beta$ APP which do not react with the $\beta A$ sequence, appear to stain the periphery and other irregular areas surrounding the neuritic plaque cores. ${ }^{17-18}$ This suggests that deposition of $\beta$ APP and its subsequent proteolysis precede and occur within the boundaries of these lesions. The fact that the $\beta A P P$ is expressed in tissues other than brain, together with the sporadic location of $\beta A$ deposits around the cerebral blood vessels, has prompted discussion on the possible non-neural origin of this protein. These findings have been reinforced by the physical similarities between the $\beta$ A filaments and those found in other amyloidoses.

The focus of our studies at Wayne State University and the University of Western Ontario has centered on the purification and characterization of the APCP. Our protocol produced highly purified APCP in good yield. This was achieved by filtration of the dispersed grey matter through a $150 \mu \mathrm{m}$ mesh, isocratic sucrose centrifugations, which eliminated most of the contaminants, collagenase and DNase digestion. The SDS lysed speci- men was submitted to sucrose density gradient centrifugation and the enriched APCP fraction was solubilized by concentrated formic acid. Insoluble lipofuscin granules were eliminated by high speed centrifugation. However, it was possible that some of the formic acid solubilized APCP could have contained some solubilized lipofuscin. We assessed this possibility by submitting a pure specimen of lipofuscin, obtained by fluorescence activated cell sorting, to formic acid treatment and subsequent chromatography under the conditions employed for the fractionation of APCP. Size exclusion HPLC of the acid treated lipofuscin supernatant yielded only one broad peak $\left(M_{r}=13 \mathrm{kd}\right)$. Amino acid analysis showed a complete absence of protein components. We concluded this fraction to be a lipofuscin chromophore of an undetermined nature. Hence, lipofuscin appears to make no contribution of the APCP preparation. Size exclusion chromatography of the formic acid solubilized APCP produced six components. Fractions 1-3, contained the $\alpha 1$-antichymotrypsin as well as other fragments of the $\beta$ APP. Fractions 4-6, on the other hand, accounted for polymeric and monomeric forms of $\beta$ A. A significant problem arose from the fact that the Superose 12 separated fractions of APCP tend to strongly adsorb to the surface of the collecting tubes. This irreversible adsorption, and consequent loss of material, can be largely prevented by the use of acid treated polyethylene tubes and the the immediate addition of small quantities of SDS to the collected samples.

Another major problem encountered during our experiments was how to eliminate the formic acid and still maintain the $\beta \mathrm{A}$ molecules sufficiently solvated for further biochemical characterization. We achieved this goal by the removal of formic acid though dialysis against high concentrations of either betaine or taurine followed by dialysis against decreasing concentrations of these zwitterions in ammonium bicarbonate. Betaine proved superior in strongly dispersing the charge densities of $\beta \mathrm{A}$, which appeared to play an important function in its polymerization, thus allowing its enzymic digestion and the subsequent assessment of $\beta A$ effects in neuronal cell culture.

APCP in situ appears to contain a rich carbohydrate moiety. 19 Lectin-FITC and lectin-gold binding sites were found to be abundant on the isolated amyloid cores as well as on the HPLC separated fractions. The saccharides carried by the APCP glycoproteins, isolated by HPLC as fractions 1-3 were released by methanolysis, and analyzed and quantitated by gas chromatography-mass spectroscopy. The general composition of these saccharides could be interpreted as compatible with both $\mathrm{N}$-linked (high mannose as well as complex oligosaccharide chains) and O-linked carbohydrates. By histochemical and immunochemical techniques, heparan sulfate proteoglycan (HSPG) has been found to be a component of the neuritic plaque. ${ }^{20}$ Furthermore, it has been hypothesized that in $\mathrm{AD}$ this proteoglycan may participate in the induction of, the deposition of, and the prevention of amyloid degradation. ${ }^{21}$ A search for this proteoglycan utilizing antibodies against HSPG, prior to and after treatment with formic acid as well as heparinase II, yielded negative results. Likewise, we found no traces of glucuronic or iduronic acids. We must emphasize, however, that failure to detect proteoglycans in our preparations could be due to the particular experimental procedures utilized in our laboratory. Another possibility is the HSPG in the NP of AD is present in such small quantities as to escape detection in the purified amyloid cores. 
By far, the most important pathogenetic issue underlying the deposition and accumulation of amyloid in the neuritic plaques is the obscure mechanisms by which an unexpected transmembrane domain of 14 hydrophobic amino acids (the C-terminal segment of $\beta \mathrm{A}$ ) appears in the extracellular environment. In the absence of mutational events (e.g. generation of a stop codon, frameshifts or post-translational modifications) which may result in the secretion of the precursor protein, the destabilization of cellular membranes becomes an alternative worthy of consideration. Direct chemical analysis and a variety of physical in vivo and in vitro measurements have clearly demonstrated multiple alterations in AD membrane and lipid metabolism. These membrane impairments might be directly associated with the etiology of AD or, at least, reflect the aberrant neuritic proliferation associated with the formation of the $\mathrm{AD}$ plaques, and not be merely the result of neuronal loss.

Major advances have been made in elucidating the chemical nature and the molecular biology of $\beta \mathrm{A}$ and its precursors. By contrast, the most compelling questions regarding its biological effects in AD remain unanswered. The deposition of APCP may be the precipitating event responsible for neuronal death. Its profuse accumulation in a diffuse form, in those cortical areas with severe neuronal dropout or condensed at the center of the plaque surrounded by dystrophic neurites, supports this view. When added to tissue cultures of sympathetic or sensory neurons, the APCP and $\beta A$, culled from the brains of patients with $A D$, appears to be highly toxic. ${ }^{22}$ In freshly plated neurons APCP and $\beta \mathrm{A}$, at low doses inhibited neuritic sprouting, a phenomenon that can be reversed upon removal of these substances. Higher concentrations $(>30 \mathrm{ug} / \mathrm{ml})$ killed the neurons in culture. The effects of APCP and $\beta A$ on established cultures are equally devastating, resulting in fragmentation of neurites and disintegration of the neuronal cell body. Apparently, both APCP and $\beta A$ condensed around the neuronal structures to exert their toxic effects, although the exact mechanism of the inhibitory actions still remains to be clarified. ${ }^{22}$ The toxic effects of the $\beta A$ on tissue cultures of hippocampal neurons has been recently reported by another laboratory. ${ }^{23}$ These findings strongly support our position that $\beta \mathrm{A}$ accumulation, as a toxic phenomenon, may participate in the pathogenesis of AD.

Last but not least, is the question of which cell is responsible for the production of the $\beta A P P$, and the mechanisms behind its abnormal processing which leads to the production of $\beta \mathrm{A}$ and its accumulation. A hematogenous source does not appear improbable at this moment, in view of the recent discovery of $\beta A P P$ in platelets as the inhibitory agent for factor XIa. An endothelial cell origin is backed by the presence of the mRNA responsible for the $\beta A P P$ in these cells, and by the finding of perivascular deposits of $\beta A$ in the majority of $A D$ cases, albeit in variable quantities. In view of the relatively abundant $\beta A P P$ and its mRNA in neurons, and the $\beta A$ presence in the neuritic plaque, these cells would appear to be the most likely source of $\beta A$. Whatever the source of the BAPP and whatever the cells and mechanisms involved in its abnormal processing, these molecules are unlikely to be just a passive and innocuous consequence of neuronal death in the evolution of the dementia of $\mathrm{AD}$.

\section{ACKNOWLEDGEMENTS}

The authors wish to thank MS. Jia Li for expert technical assistance. These studies were supported, in part, by grants from the Atkinson
Charitable Foundation of Toronto, Ontario (M.J. Ball) the National Heart, Lung and Blood Institute (HL32870; K.C. Palmer).

\section{REFERENCES}

1. McGeer PL, Akiyama $\mathrm{H}$, Itagaki $\mathrm{S}$, et al. Immune system response in Alzheimer's disease. Can J Neurol Sci 1989; 16:516-527.

2. Rogers J, Luber-Narod J, Styren SD, et al. Expression of immune system-associated antigens by cells of the human central nervous system: relationship to the pathology of Alzheimer's disease. Neurobiol Aging 1988; 9: 339-349.

3. Gray EG, Paula-Barbosa M, Roher AE. Alzheimer's disease: paired helical filaments and cytomembranes. Neuropathol Appl Neurobiol 1987; 13: 91-110.

4. Roher AE, Palmer KC, Chau V, et al. Isolation and chemical characterization of Alzheimer's disease paired helical filament cytoskeletons: differentiation from amyloid plaque core protein. $\mathrm{J}$ Cell Biol 1988; 107: 2703-2716.

5. Kang J, Lemaire GG, Unterbeck A, et al. The precursor of Alzheimer's disease amyloid A4 protein resembles a cell surface receptor. Nature 1987; 325: 733-736.

6. Golde TE, Estus S, Younkin LH, et al. PCR amplification of reverse transcribed RNA reveals a fourth alternatively spliced $\beta A P P$ and mRNA. Soc Neurosci Abstr 1989; 15: 648.

7. Goldgaber D, Lerman MI, McBridge OW, et al. Characterization and chromosomal localization of a cDNA encoding brain amyloid of Alzheimer's disease. Science 1987; 235: 877-880.

8. Ponte P, Gonzalez-DeWitt P, Schilling J, et al. A new A4 amyloid mRNA contains a domain homologous to serine proteinase inhibitors. Nature 1988; 331: 525-527.

9. Tanzi RE, McClatchey AI, Lamperti ED, et al. Protease inhibitor domain encoded by an amyloid protein precursor mRNA associated with Alzheimer's disease. Nature 1988; 331: 528-530.

10. Kitaguchi N, Takahashi Y, Tokushima Y, et al. Novel precursor of Alzheimer's disease amyloid protein shows protease inhibitory activity. Nature $1988 ; 331: 530-532$.

11. Oltersdorf T, Fritz LC, Schenk DB, et al. The secreted form of the Alzheimer's amyloid precursor protein with the Kunitz domain is protease nexin II. Nature 1989; 341: 144-147.

12. Van Nostrand WE, Wagner SL, Suzuki M, et al. Protease nexin II, a potent antichymotrypsin, shows identity to amyloid $\beta$-protein precursor. Nature 1989; 341: 546-549.

13. Smith RP, Higuchi DA, Broze GJ. Platelet coagulation factor XIainhibitor, a form of Alzheimer amyloid precursor. Science 1990; 248: $1126-1128$

14. Selkoe DJ, Podlisny MB, Joachim CL, et al. Beta amyloid precursor protein of Alzheimer's disease occurs as 110 to 135 kilodalton membrane associated proteins in neural and non-neural tissues. Proc Natl Acad Sci USA 1988; 85: 7341-7345.

15. Weidemann A, Konig G, Bunke D, et al. Identification, biogenesis, and localization of precursors of Alzheimer's disease A4 amyloid protein. Cell 1989; 57: 115-126.

16. Miller DL, Currie JR, Iqbal K, et al. Relationships among the cerebral amyloid peptides and their precursors. Ann Med 1989; 21 : 83-87.

17. Perry G, Lipphardt S, Mulvihill P, et al. Amyloid precursor protein in senile plaques of Alzheimer disease. The Lancet 1988; 2: 746.

18. Palmert MR, Podlisny M, Witker DS, et al. Antisera to an aminoterminal peptide detect the amyloid protein precursor of Alzheimer's disease and recognize senile plaque. Biochem Biophys Res Comm 1988; 156: 432-437.

19. Szumanska G, Vorbrodt AW, Mandybur TI, et al. Lectin histochemistry of plaques and tangles in Alzheimer's disease. Acta Neuropathol 1987; 73:1-11.

20. Snow AD, Willmer JP Kisilevsky R. Sulfated glycosaminoglycans in Alzheimer's disease. Hum Pathol 1987; 18: 506-510.

21. Snow AD, Wight TN Proteoglycans in the pathogenesis of Alzheimer's disease and other amyloidosis. Neurobiol Aging 1989; 10: 481-497.

22. Roher AE, Ball MJ, Bhave SN, et al. $\beta$-amyloid from Alzheimer disease brains inhibits sprouting and survival of sympathetic neurons. Biochem. Bipohys Res Comm 1990; 174: 572-579.

23. Yankner, BA, Duffy LK, Kirschner DA, Neurotrophic and neurotoxic effects of amyloid $\beta$-protein: reversal by tachykinin neuropeptides. Science 1990; 250: 279-282. 